\title{
Challenges to the Development of Carbon Markets in China
}

\author{
Alex Y. Lo \\ Griffith School of Environment, Griffith University, Gold Coast, Queensland, Australia \\ (currently at the Kadoorie Institute, the University of Hong Kong, China)
}

\begin{abstract}
China has introduced several pilot emission trading schemes to build the basis for a national scheme. The potential scale of this initiative raises prospects for a regional carbon trading network as a way to further engage other major Asian economies. However, the Chinese carbon markets rest upon a unique political-economic context and institutional environment that are likely to limit their development and viability. This article offers an overview of such structural economic and political constraints. Four main challenges are identified, namely, inadequate domestic demand, limited financial involvement, incomplete regulatory infrastructure, and excessive government intervention. The first two challenges concern economic dimensions and may be partially addressed by the incentives created by the newly introduced emission trading schemes. The other two are more deeply entrenched in the dominant political system and governing practice. They require fundamental changes to the ways in which the state and the market interact. The success of China's carbon market reform depends crucially on the ability of the ongoing efforts to transform the distorted state-market relationship.
\end{abstract}

Keywords: carbon market; emission trading; climate governance; political economy; developing country; China 


\section{Introduction}

Over the past decade, carbon emission markets have risen to become the dominant form of institutions for climate change mitigation (Ellerman, Convery, \& Perthuis, 2010; Grubb, 2012; Grubb, Laing, Counsell, \& Willan, 2011; Mol, 2012; Pezzey \& Jotzo, 2013; Spaargaren \& Mol, 2013). Global carbon trades recorded a soaring market value of US\$176 billion in 2011 (Kossoy \& Guigon, 2012, p. 10). Approximately US\$23 billion originated from the trading of secondary carbon offsets under the Kyoto Protocol's market mechanisms, notably the Clean Development Mechanism (CDM).

Global carbon finance needs to be scaled up by an order of magnitude in the second commitment period of the Kyoto Protocol. Some commentators see opportunities from outside the project-based CDM. Allowance-based market mechanisms may be able to engage emerging economies in ways similar to those which operate in Europe, i.e. the European Union's (EU) emission trading scheme (ETS) (Grubb, 2012; Perdan \& Azapagic, 2011). Major Asian economies are taking up this trend, including Tokyo (Japan), South Korea, China, Kazakhstan, and India. China, the world's largest emerging market, is seen to have great potential for large-scale carbon trading (Fankhauser, 2011; Guan \& Hubacek, 2010; Jotzo, De Boer, \& Kater, 2013; Wang, 2013).

China declared a plan to introduce ETSs in the late 2011, raising prospects for further engagement with other major Asian economies through a regional carbon trading network. Seven pilot ETSs have come to operation in the country since 2013 (Han, Olsson, Hallding, \& Lunsford, 2012; Jotzo, 2013; Lo, 2012). The short-term goal is to establish transprovincial and trans-regional ETSs in transition to a national ETS. The prospective national scheme may eventually become the world's second largest after the EU ETS and mark a major step forward in creating a global carbon market at a potentially higher value than the oil market. This has brought some hope to advocates of a common carbon price across the globe.

From the Chinese government's perspective emission trading has multiple benefits. According to Wang and Duan (2013), both officially involved in the design of China's ETSs, the emission trading programme can, on the micro-economic level, help minimize the costs 
of GHG emission reduction, develop new business opportunities, promote business engagement, and establish links with international carbon markets. At a macro-economic level, a successful national ETS will contribute to the transformation to a low-carbon economy and strengthen China's role in international climate change negotiations (Partnership for Market Readiness, 2013; Sun, 2012).

However, China's carbon pricing policies have been developed in a different political-economic context. The majority of the existing mandatory ETSs operate in mature market economies safeguarded by a liberal democratic regime. In contrast, China is a developing market economy with socialist political legacies (Lo, 2010; Tsang \& Kolk, 2010). Also it currently does not assume any binding commitment to absolute emissions reduction. These political realities have created considerable institutional barriers to the development of domestic carbon markets in China.

This article offers an overview of such structural economic and political constraints, and discusses the main challenges to the development of carbon markets in China. It is based on an extensive review of official policy documents, published research papers, and relevant news reports. The remainder of this article is divided into three sections. The first one describes the context of carbon trading, followed by an elaboration on the national policy context in which China's carbon market and pilot ETSs are situated. The third explains the structural hurdles to the development of domestic carbon markets. Implications are discussed in the conclusion.

\section{The political-economic context of carbon trading}

The EU ETS is the world's largest carbon market, which is worth US\$148 billion and has entered Phase III (2013-2020) of its implementation. Outside Europe, progress has also been made in the Anglo-American world, with ETSs emerging in New Zealand, Australia, California and ten Northeastern states of the U.S., British Columbia and Quebec (Canada). Carbon markets have become popular because they have enabled the formation of business alliances favouring GHG emissions reductions and enabled businesses to imagine a cycle of investments, profits, and growth centered on these markets. These markets offer a new 
avenue for economic growth operating by re-organising the role and power of the state (Bumpus \& Liverman, 2008; Newell \& Paterson, 2010).

It is widely believed that carbon markets are established in the liberal-capitalist world as a product of a coalition of financial, political, and environmental actors (Bumpus and Liverman 2008; Paterson 2010, 2012). The political momentum for carbon trading was driven by government bodies forming powerful allies with major industries. In particular, some transnational oil giants and the financial sector formed advocacy groups and significantly influenced governments' decisions to introduce ETSs in Europe and the U.S. (Meckling, 2011; Newell and Paterson 2010). The advocacy coalition manifested as a bottom-up force driving the process of market construction (Meckling, 2011; Paterson, 2010, 2012). Compatible norms of liberal market economic are pivotal to the market success.

The broader political economic context within which China's carbon markets gain force varies from those of the established liberal-capitalist regimes. The country does not have a long history of neoliberalization of environmental policy and the state machinery is not designed to run market mechanisms (Gilley, 2012; Lo, 2013). China has formally

embraced the notion of "socialist market economy" since its $14^{\text {th }}$ National Congress held in 1992. The post-Mao market reforms have seen the state retaining substantial control over critical industries, commodity markets, and the economy generally. Political power is largely centralized, particularly in the formulation of national climate change policies, whereas the influence of non-state actors remains peripheral. The authoritative governing practice could undermine the capacity of decentralised economic and market institutions to support the use of market-based policy instruments for mitigating environmental impacts.

The concentration of state power indicates a notable departure from the view that carbon markets are primarily powered by a finance-led coalition. This raises questions about how the Chinese domestic carbon markets operate in such a different context and what challenges constrain their further development. An overview of relevant policy background could help address these questions.

\section{China's climate policy and recent development}




\subsection{Towards a market-based approach}

China has risen to the world's second largest economy and the largest national source of GHGs, producing 25.4 per cent of the world's total $\mathrm{CO}_{2}$ emissions, or 5.9 tonnes $\mathrm{CO} 2$ per capita in 2011 (International Energy Agency, 2013: 52 and 103). At the 2009 United Nations Summit on Climate Change, the then Chinese President Hu Jintao indicated that China will not accept mandatory national targets for emission reduction until major developed countries take the lead. Later, at the Copenhagen conference, the Chinese delegate reportedly attempted to block the development of the Copenhagen Accord (Christoff, 2010). China was blamed for failing to assume tougher emission reduction targets and for not working in meaningful ways with the international community.

Nonetheless, China has made some progress back home (Jiang, Zhuang, Miao, \& He, 2013; Zhang, 2007, 2011). As the world's leader in renewable energy production (Schroeder, 2009), carbon intensity has declined over the last two decades, although this came with rapid growth in $\mathrm{CO}_{2}$ emissions per capita (Figure 1). Prior to the Copenhagen negotiations, the country substantially scaled up its unilateral commitment: carbon intensity down by 40-45 per cent below 2005 levels by 2020. Official climate change policy programmes have been put in place since the second half of 2000s. In 2007, China launched the National Climate Change Program (National Development and Reform Commission, 2007). In 2008, the White Paper on China's Policies and Actions for Addressing Climate Change was released (State Council, 2008).

\section{[FIGURE 1 ABOUT HERE]}

China's climate policy regime indicates two key features that influence the development of domestic carbon markets. Firstly, economic interests are deeply embedded into the climate policy framework - more so than in other major developed countries. The 2007 and 2008 policy documents are essentially an energy blueprint and none of them make reference to the Ministry of Environmental Protection (MEP), the national environmental agency, or its predecessor (Lo, 2010). Climate change policies are formulated and implemented by the NDRC, which is a macroeconomic planning and management agency under the State Council (commonly known as the 'central government'). The NDRC is a 
more powerful administrative body, with its own energy and environmental departments, than the MEP. It is worthwhile noting that the NDRC is a co-chair of the National CDM Board of China, whereas the MEP is only a board member. The dominant role of the NDRC indicates the strategic position of climate policy as being situated in the context of energy security and conservation (Lo, 2010; Tsang and Kolk, 2010). Climate change impacts are understood primarily in macro-economic terms (Sautter, 2009).

Second, China remains a planned economy in some aspects, despite the tendency of decentralisation in environmental policy-making (Mol, 2009). Climate change is treated as a technical issue by political elites and state administrators, for which technical fixes are concentrated on energy saving measures and introduced in a top-down fashion (Lo, 2010; Tsang and Kolk, 2010). Centrally planned policy guidelines are published in a periodic legislative document known as the 'Five-Year Plan for National Economic and Social Development' (FYP). FYPs prescribe national economic and social directions and coordinate policy priorities. FYPs are the most prominent strategic blueprint for the country. Climate change was not written into any FYP until the $11^{\text {th }}$ FYP which covered the period of 20062010. Specifying mandatory targets is a key feature of FYPs and the $11^{\text {th }}$ FYP addressed climate change by declaring commitment to an energy intensity target, i.e. 20 per cent reduction by 2010. Throughout this period, GHG control in China was achieved largely through direct regulation. A range of administrative and political measures were deployed, including government-funded incentives to support installation of energy-saving equipment, top-down imposition of energy-saving targets on energy-intensive industries, and forced closure of inefficient power plants and factories. Market-based instruments were used to play a limited role.

Although China's institutional innovations have produced positive environmental outcomes, they have not contributed to absolute reductions in emissions and energy use (Mol, 2009). Success has been achieved only in relative terms: between 2000 and 2011, China’s carbon intensity ( $\mathrm{CO}_{2}$ emissions per unit GDP) dropped by 19 per cent, but the level of $\mathrm{CO}_{2}$ emissions more than doubled (140 per cent) (International Energy Agency, 2013: 97 and 52, respectively). The $11^{\text {th }}$ FYP received marginal success against the emission reduction target. China managed to lower energy intensity by 19.06 per cent by the end of 2010. This result, 
however, involved an extended use of the 'visible hand', i.e. political intervention, such as electricity rationing ( $\mathrm{Wu}, 2011)$, and formal coercive requirements on energy consumption (Gilley, 2012). As part of last-ditch efforts to meet the target, a number of provinces were forced to close large swathes of industrial capacity, resulting in "black-outs" of some industries and certain cities towards the end of 2010 (Gilley, 2012; Han et al., 2012). The marginal success came with high costs.

This experience prompted the central government to seek a different strategy. Economic policy instruments immediately received attention from senior government officials. Carbon taxes and cap-and-trade mechanisms are prime examples of these instruments being put under serious consideration by the central government.

\subsection{Tax or trading? Or both?}

Carbon trading entered an uncertain period in 2009, when the world economy stumbled and the Copenhagen Conference failed to produce substantive agreements on Post-2012 commitments (Perdan and Azapagic, 2011). As the world economy began to recover from the financial turmoil, China cast a vote of confidence for the carbon market. Towards the end of 2010, senior Chinese officials declared their ambition to establish a national ETS to curtail its growing GHG output. In October 2011, the National Development and Reform Commission (NDRC), China's top economic planning agency, granted official approval to seven carbon trading pilot projects.

However, carbon taxes were actually the first preference (Wu, 2011; Han et al., 2012; Yu and Elsworth, 2012). Carbon taxation was listed by the Ministry of Finance (MOF) as a promising carbon pricing approach as early as 2007, and several peak government agencies and research institutions were brought together to undertake preliminary research into its feasibility. This policy approach received support from a group of prominent government members and academic economists as a practical option for China in the early stages of its transition to a low-carbon economy in advance of a national ETS (Fan et al., 2011: 40). A new proposal for a Chinese carbon tax was submitted to the MOF for official consideration in the early 2012, with hopes to roll it out in the second half of the $12^{\text {th }}$ FYP period, which 
covers the period of 2011-2015 (Lin \& Yang, 2012). It is worth noting that the carbon tax project is principally coordinated by the MEP, the MOF and other finance agencies, whose influences in the country's climate policy regime are modest.

Carbon taxes are a fiscal measure that harnesses market forces for controlling carbon pollution in ways opposite to carbon trading. Carbon taxes involve setting a fixed price for carbon emissions and allowing the quantity of emissions to fluctuate, whereas carbon trading involves a fixed quantity of emissions and allowing the price of carbon emissions to fluctuate. Cap-and-trade mechanisms produce efficient outcomes by allowing the market to determine the right price, and are therefore incompatible with carbon taxes which preclude carbon prices from changing. The Chinese government has a choice between the two economic instruments.

Pezzey and Jotzo (2013) argue that carbon taxes are a fiscally attractive option for China provided that certain conditions are met. Others, such as Fan et al (2011) and Lin and Yang (2012), believe that the two policy instruments can co-exist in a given period of time. While it is possible in theory for carbon taxes and carbon trading to co-exist in a policy mix (Sorrell \& Sijm, 2003), their potential conflicts should not be under-estimated. Carbon taxes, however, are primarily a domestic policy measure restricted to the implementing country. Such mechanisms could not support China's growing desires for engaging in international or regional climate change policy regimes, such as the EU ETS or potentially its Asia-Pacific equivalent. In contrast, trading mechanisms allow international linking and can enhance the scale of domestic carbon markets and China's capacity for engaging in the governance of international carbon markets. Carbon trading has greater global political and economic implications and therefore proven to be a preferred option being given higher political priority than the idea of carbon tax, which has only received scholarly appreciation and ministerial consideration.

The political preference for ETS is evident in the $12^{\text {th }}$ FYP. Although the government promises an annual GDP growth of 7 per cent under the $12^{\text {th }}$ FYP period, it assumes ever greater environmental commitments than under any previous FYP. Prominent targets include an energy intensity reduction of 16 per cent and carbon intensity reduction of 17 per cent by 2015 - the first time when a $\mathrm{CO}_{2}$ emission control target is written into a FYP. Carbon 
trading has also found its way onto the official agenda. Confirmation comes from a brief statement in the $12^{\text {th }}$ FYP that the country will embark on the building of domestic carbon markets (State Council, 2011a: Chapter 21). This commitment is official and granted at the highest level. More details were provided later in the thematic FYP on GHG control released by the State Council (2011c) reiterating the commitment to domestic carbon trading. The political endorsement articulated in these FYPs is authoritative, giving impetus to a top-down approach by which the market construction project proceeds.

A formal notice of implementation outlining the Chinese ETS program was released in October 2011 by the NDRC (2011). The brief document states that, adherent to the master plan of the Community Party and the State Council (i.e. the $12^{\text {th }}$ FYPs), the NDRC will gradually create a domestic carbon trading market (National Development and Reform Commission, 2011). The announcements by the State Council and the NDRC, its economic arm, have not only confirmed the political priority of establishing a compliance carbon market, but also painted a clearer picture by appointing seven pilot sites across the country, including two provinces (Guangdong and Hubei) and five cities (Beijing, Tianjin, Shanghai, Chongqing, and Shenzhen) (Table 1). Five of these pilot schemes commenced in 2013 and the remaining two (Chongqing and Hubei) were scheduled for 2014. Recorded carbon prices varied across these sites - from RMB26.96 (USD4.31) in Tianjin to RMB67.27 (USD10.75) in Shenzhen, but market transactions, by volume of treading, were concentrated in in the southern region (i.e. Guangdong, Shenzhen, and Shanghai) (Wang, 2014). The short-term goal of this policy programme is to establish trans-provincial and trans-regional ETS in transition to a national scheme. The timeframe for the national ETS has moved from 2015/2016 to 2018 (S. Wang, 2014).

\section{[TABLE 1 ABOUT HERE]}

However, China's climate change policies, including the prospective national ETS, are formulated in the context of continuing economic development. Although considerable political efforts are being organised to put a price on carbon, the overriding desire for economic growth and the interventionist planning tradition have created practical obstacles to China's success on the carbon trading front. These challenges are explained in the next section. 


\section{Structural constraints on the development of domestic carbon market}

'Cap and trade' mechanisms are driven by formal regulations and/or voluntary business commitments. In addition, they require a robust regulatory and legal framework and a liberal market economy to produce efficient outcomes. The Chinese carbon market falls short of the basic requirements and fails to play a functional role. The Chinese experience is characterised by inadequate domestic demand, limited financial involvement, incomplete regulatory infrastructure, and excessive government intervention.

\subsection{Inadequate domestic demand}

Adequate market demand is essential when building a functioning carbon market. It can be driven by a binding emission cap which puts a limit on the amount of GHG emissions that firms are allowed produce, or by their own voluntary commitment to cutting emissions. Such an absolute emission cap has not been introduced in China, while the market demand driven by current carbon intensity reduction targets is not strong enough to support the new industry.

Since China is not subject to legally binding emission targets under the Kyoto Protocol, the central government lacks motivatation to cap GHG emissions at a national level. The absence of emission caps has created weak demand for emission allowances or offsets (Han et al., 2012; Yu \& Elsworth, 2012). Domestic carbon trades have been predominantly driven by voluntary commitments. However, Chinese firms are under no obligation to hold carbon emissions credits for the pollution they produce, except for those now being covered by the pilot ETSs, which are by no means driven by any Kyoto-based emission target. Not many Chinese firms are motivated to purchase emission reduction credits to fulfil their corporate social responsibility and the majority lack motivation to act (Huang, 2013). The lack of expertise and capacity has also discouraged corporate participation in global carbon trading (Wang \& Pan, 2009).

China is a net exporter of emission reduction credits. Under the Kyoto Protocol, Annex I countries could fulfil part of their compliance requirement by buying certified 
emission reductions (CERs) from non-Annex I countries through the CDM. China is the biggest supplier of CERs in the CDM market. In the absence of strong domestic demand, the majority of the emission reductions produced are sold to international buyers (Han et al., 2012; Xinhua News Agency, 2011). Besides CDM-driven activities, domestic deals are fairly limited.

Ironically, the paucity of domestic carbon trades does not prevent the rapid expansion of carbon markets in the country. Carbon trading facilities in China have proliferated since 2008. This is an exponential quantitative growth coupled with over-investments in trading infrastructure at the sub-national levels. At least 42 formal environment/carbon exchanges have been set up in various coastal and inland provinces, and even counties (AUTHORS, 2013). Most of these exchanges focus on the flourishing carbon trading business. A growing number of carbon trading facilities and local ETSs are expected to come into operation within a short timeframe (Kossoy and Guigon, 2012; Xinhua News Agency, 2011). These numbers should be understood in the context of the European and American carbon markets in which only several exchanges handle most of the global carbon trades.

The proliferation of carbon exchanges indicates the fragility of China's carbon markets. The emergence of these exchanges is driven by an opportunistic attempt to engage in speculative activities and reap benefits for the local economy (Xinhua News Agency, 2011) - a modern 'gold rush'. As noted by Liu (2010), carbon trading activities in China remain patchy and, until recently, there was no dedicated authority to coordinate these activities. There are more sellers than buyers in these markets due to weak domestic demand and strong incentives to sell emission reductions abroad. This is particularly true for smaller exchanges established in second- or even third-tier cities, where the lack of proper planning and coordination have resulted in intense competition among themselves for the already scarce supply of trading opportunities (AUTHORS, 2013). Reportedly, in the three years since its establishment, only three millions tonnes of carbon emissions were traded in the China Beijing Environment Exchange, the flagship carbon market located in the nation's capital, falling short of the daily trading volume in Europe (China Business News, 2011). Marginal surplus is recorded only in Shanghai. Few transactions took place in its counterparts in Changsha and Shenzhen since their inception. Small local exchanges that have attracted 
limited capital flows are doomed to premature closure (Xinhua News Agency, 2011). The scale and viability of individual carbon exchanges have been compromised by the weak domestic demand, a problem aggravated by their unchecked proliferation in the preceding years.

Given the shortage of trading opportunities these carbon markets only play a peripheral role. They merely demonstrate the political efforts of local government leaders competing to showcase their achievements, and operate as a platform for organising public relations and research-and-development activities (Han et al., 2012). These fragmented markets are not functioning, although they help build capacity for supporting major developments in the national carbon market. The absence of emissions caps has severely limited their vibrancy.

\subsection{Limited Involvement by Private Finance}

Commercial financial services are a critical element of a functioning and efficient carbon market (Bayon, Hawn, \& Hamilton, 2009). In China, however, economic and financial institutions 'have virtually no role to play in advancing environmental interests' (Mol, 2006, p. 52). Mol (2006) suggests that these institutions feel no pressure or see any market opportunity from active engagement. This view accurately describes the current situation of climate finance and carbon trading in China specifically.

According to the 2012 China Climate Finance Report, public funds currently dominate the total investment in climate finance in China (Wang et al., 2012; see The Climate Group, 2013 for a concise English version). In 2011, state-owned banks offered US\$294 billion and direct government climate spending amounted to \$US41 billion, whereas mainstream private sector investment, such as domestic and foreign bank loans, accounted for around US\$10 billion (The Climate Group, 2013, p. 2). This shows that private funds are not the main source of climate finance in China. Existing systems have not been successful in directing private capital to the carbon financial markets. In contrast, private investment was the main source of climate mitigation finance globally (Grubb et al., 2011; Stadelmann, Michaelowa, \& Roberts, 2013). 
A number of structural problems have undermined the initial growth of the carbon financial industry in China. Firstly, the regulatory and policy systems are not conducive to the deployment of climate finance. Regulatory standards and official data on emissions are far from complete and consistent, making it difficult for financial institutions to assess the economic and environmental viability or risk of applications. The legal system remains incomplete and fragile. This raises the risk of financial frauds and gives little protection to investors in the event of financial breakdowns (The Climate Group, 2013; Wang, Liu, \& Chen, 2012).

Second, domestic financial institutions themselves lack both the incentive and capacity for participation. Motivation to finance emission mitigation is low as climate change is not seen as a fruitful investment option by domestic financiers. Although state-owned banks consider climate related investment as a corporate social responsibility issue, they are yet to include climate impacts as key considerations of business development (Wang et al., 2012, p. 40; The Climate Group, 2013, p. 4). Investors are not very optimistic about the prospects of financial products linked to climate change. Commercial banks are at a stage of 'wait and see' and have only recently set up rudimentary carbon asset management services and funds. Many of them do not possess the adequate knowledge and expertise in climate finance. Progress is slow in developing climate financial products, such as climate debentures and climate insurance.

Carbon trading is a more specific area of climate finance that requires a functioning market to deliver efficient outcomes. The regulatory and policy environment is, again, the key determinant of success or failure. According to Adams (2013), the central government forbade Chinese banks and certain other financial institutions from getting involved in the CDM and appears reticent to allow them to participate in the China's domestic carbon markets. Securities regulators do not view carbon trading as falling under the purview of 'finance' and tend not to assume direct responsibility for regulating carbon markets (Adams, 2013). Indeed, there has been 'a culture of distrust in business', limiting access of some corporations and financiers interested in carbon trading to the policy arenas (Wang, 2013, p. 273). Carbon asset management firms, for instance, have no significant impact on the institutional development of Chinese voluntary carbon markets. Neither the central nor local 
governments consider these firms indispensable components of domestic carbon trading systems (Huang, 2013).

The market structure in its current form does not appear attractive to businesses and financial institutions. Few Chinese businesses take corporate social responsibility seriously and they have no legal obligations to curb their emissions. This leads to low demand for carbon credits and related financial services. On the supply side, Chinese carbon exchanges are currently only allowed to operate spot markets. Globally, these markets account for only a small share of the carbon trades, whereas futures markets dominate (Wang et al., 2012). For carbon trading to thrive, exchanges must have the capacity to allow derivatives trading and securities businesses, but the central government is reluctant to offer derivatives and securities because of risk-management concerns (Adams, 2013). As specified in a decree released in 2011 (State Council, 2011), special permissions are required for local exchanges to undertake these activities. The limited trading options are likely to discourage financial investors.

\subsection{Incomplete regulatory infrastructure}

Compliance carbon markets are regulation-driven. Under an ETS, firms are required to surrender emission permits for a given amount of emissions produced. Legislation is imperative to establishing the legal status of emission permits or allowances. Enforcement and punishment are required in the event of non-compliance or misconduct, where permits are not surrendered as stipulated, prescribed trading rules are violated, or data reporting is found to be misleading. Moreover, the number of permits a firm has to hold is assessed against available emissions data. An accurate and consistent system for measurement, monitoring, reporting and verification is essential to ensure effective regulation of firms covered by an ETS.

China's regulatory infrastructure for carbon trading is far from complete. There are considerable challenges in setting up robust monitoring, reporting and verification mechanisms, which remain current in Europe and more so in China, where legal enforcement is constantly a problem confronting all levels of the society. Currently, there are no national 
regulations specifically for emission trading, and the on-going ETS programme proceeds as an administrative operation. While any assessment of regulatory performance in advance of the implementation of the pilot schemes is inevitably inconclusive, it is useful to review other relevant regulatory experiences as a reference point, such as the $\mathrm{SO}_{2}$ ETS.

The notion of $\mathrm{SO}_{2}$ emission trading has been in China since the 1990s. Although local governments had set up regulations for the $\mathrm{SO}_{2}$ ETSs, the lack of transparency in actual regulatory practice remains a concern. Emission trading rules are not clearly articulated, and enterprises have little assurance that the trading arrangements could protect their rights as 'under-the-table' negotiations and corruptions dominate (Tao \& Mah, 2009). Market transparency is also limited due to the absence of an effective information management and disclosure system (Tao and Mah, 2009). Furthermore, the punitive mechanisms are poorly constructed; fines are too low to discourage non-compliance (Chang \& Wang, 2010; Mol, 2009). Violation for the second time is tolerated: a firm would not be fined twice for the same polluting activity in the event of non-compliance, consequently creating little motivation for buying or selling emission permits (Chang and Wang 2010). Locally there is strong political resistance to the enforcement of environmental laws, including those relating to emission caps that are thought to be detrimental to the economy ( $\mathrm{Liu} \& \mathrm{Xu}, 2012$; Zhang, 2007). Bureaucrats generally have low motivation to consistently enforce legal provisions.

Allocation of emission permits would be a source of faults if monitoring, reporting and verification mechanisms lack accuracy and consistency. This is the current situation in China, where official emissions data lack reliability (Zhang, 2011) and the current systems are predominantly based on self-reporting (Tao and Mah, 2009; Chang and Wang, 2010). Regulated firms prepare emissions reports themselves and are subject to occasional inspections by environmental agencies. They are only required to report fuel inputs and emissions are not monitored on a regular basis, if ever. Manipulation of emission data is not uncommon under some allocation methods (Tao and Mah, 2009). Permit allocation remains arbitrary in the absence of reliable information on which it is based. China is not known for effective legal enforcement and disclosure of sensitive environmental information (Mol, He, \& Zhang, 2011). 


\subsection{Excessive state intervention}

The promise of economic efficiency relies upon the existence of a perfectly functioning market. A necessary condition for an ETS to work is that prices are allowed to fluctuate towards market equilibrium. The idealised setting is a free market economy in which prices are determined by market dynamic and not controlled by a single party. This economic assumption has lost validity in actual market settings (Spash \& Lo, 2012). The European experience suggests that market power does exist and the power industry, often dominated by a handful of large corporations, has the ability to engage in activities such as mark-up pricing, price discrimination and manipulation (Spash \& Lo, 2012).

The current situation of the power market in China has violated that assumption in a different dimension. Key economic policies are formulated by central authorities and state intervention continues to affect every aspect of economic life. In this country power prices are actively regulated by a central authority. Despite recent electricity market reforms, electricity prices remain under the central government's control. The Department of Price, a subsidiary of the NDRC, is responsible for moderating the prices of key commodities, including electricity. Through its administrative arm the central government sets a specific price for almost every newly built generation plant since 1985 (Du, Mao, \& Shi, 2009). There are large variations in the regulated prices between or even within plants. The regulation of wholesale electricity price proves to be ineffective (Du et al., 2009). Criteria for price control have been arbitrary.

Price control means that the carbon price under the ETS would reflect political judgement, rather than marginal cost of production. Regulated electricity companies would be prevented from passing the full cost to electricity users who are expected to adjust their power consumption in response to price signals, as the central government is highly concerned about the impacts of volatile prices on the economy, particularly the possibility of inflation under the carbon price ( $\mathrm{Wu}, 2011)$. A World Bank report predicts that under a Chinese ETS which covers the power industry, the Department of Price would play a central role in managing the cost of carbon and its fluctuation (Kossoy and Guigon, 2012). The managed carbon price would effectively become a kind of carbon tax in co-existence with a cap-and-trade mechanism, in which both prices and emissions quantity are subject to some 
form of state control. Prospects for economic efficiency are, however, uncertain (Sorrell and Sijm, 2003).

The regulatory experience with the Chinese $\mathrm{SO}_{2}$ ETS has demonstrated the limited scope for the market to operate free from arbitrary political manipulation. The $\mathrm{SO}_{2}$ emission trade prices are largely modulated or instructed by the state depending on the discretion of individual government officials (Tao and Mah, 2009). Emission trading transactions have been subject to administrative intervention. In some cases the government dominates the entire transaction process, including negotiation on trading price, trading volume and terms of permit ownership (Tao and Mah, 2009). Market competition has only recently come to existence in China's regulated power sector in which political bargaining is prevalent. The legacy of planned economy has created distortions to the ETS.

Given the tremendous economic implications of GHG control, the central and local governments are tempted to execute the 'visible hand' by modulating prices as they do regularly to manage the economy. It is therefore uncertain as to how the power sector can be brought into the prospective ETS. Certainly some form of policy intervention is occasionally needed to manage residual risks and maintain market order, but the Chinese government has a history of regularly and intensively controlling the macro-economy through administrative means. Gilley (2012) has noted that a key element of China's climate policy discourse is the extensive use of authoritative power. This governance tradition comes into conflict with the theoretical requirements for an emission trading regime to operate efficiently.

\section{Conclusions}

China has made efforts on emission reduction in the context of continuing economic development. The conditional commitment is evidenced by the declared preference for intensity targets and compatible economic mechanisms recently adopted. Carbon taxes could fit the domestic context, whereas domestic carbon trading in early stages lacked coordination and merely served to reap short-term benefits and improve public image without demonstrating major environmental achievements. However, carbon trading has proved to be politically more attractive. High-level coordination is underway and centrally approved ETSs 
are up and running. Political resistance has softened; local emissions caps are being introduced and national caps are imaginable in medium term. The real challenges are, however, how the regulation-driven carbon market system works effectively with the state machinery which is not primarily designed to support such system.

China's carbon markets operate in a unique political economic context that accounts for some of the structural barriers limiting their growth. This article has identified four main challenges to the carbon market development in China, namely, inadequate domestic demand, limited financial involvement, incomplete regulatory infrastructure and excessive government intervention. The first two concern economic dimensions. A key hurdle underlying these economic challenges is the absence of a nationwide emission cap. Nevertheless, Chinese state leaders appear to be increasingly aware of the potential benefits of active engagement in global carbon trading, as demonstrated by their approval of the pilot ETSs. There will be long-term benefits to the country if carbon trades eventually surpass the oil market and dominate the global market. In addition to mounting international pressures, the fact that China's economic growth and energy demand have begun to slow down in recent years may also reduce political resistance to introducing binding emission limits at the national level.

In this light, it is possible that some form of emission cap may come into existence in this country in the next ten years or so, creating demand for emission allowances and giving the necessary economic energy to the domestic carbon market. This can also address, at least partially, the problem of limited financial involvement. When regulated firms are required and motivated to curb emissions or purchase emission allowances or offsets, private financial institutions will become more willing to engage in the carbon market. Banks, financial intermediaries and consultancies will gain experience and capacity over time through pilot schemes and other private or public initiatives. Proper changes in policy arrangements can address the lack of demand and investment which creates impediments to market growth. Capping GHG emissions at the national level, in particular, will be an effective way for strengthening China’s carbon markets.

The other two challenges tend to be institutional and to arise from the unique political system of China, which operates as a 'social market economy'. The lack of a robust 
regulatory and legal framework, and the excess of government intervention are amongst the more intractable governance issues. Modest changes in governing practice have occurred through the tendency for decentralisation of environmental policy-making. However, some of the institutional barriers are rooted in the ways in which the larger system operates and maintains its legitimacy. For example, improving the regulatory and legal framework for GHG emission reporting will enhance transparency; but it may open up some sensitive energy security issues that the ruling regime has traditionally been very cautious about (official data on provincial and municipal GHG emissions are currently not open to public).

Furthermore, the ability to exercise direct government intervention in the macroeconomy (e.g. moderating utility prices) proves to be important for the non-elected ruling regime to maintain economic and social stability in this country. Political efforts are required to address these deeply entrenched institutional barriers and redefine the role of the state. Although the ongoing ETS programme will introduce new institutional practices at various scales, the success of China's carbon market reform crucially depends on the ability of these new institutions to transform the distorted state-market relationship. To strengthen the carbon markets, policy-makers should reconsider the role of macro-economic agencies, such as the Department of Price, and state ownership of big GHG emitters, notably oil companies.

Further research is needed to ascertain how the state and the market interact to balance conflicting political and economic requirements.

\section{References:}

Adams, M. (2013). Trials and tribulations: China experiments with carbon trading. Hong Kong: The Economist Intelligence Unit.

Bayon, R., Hawn, A., \& Hamilton, K. (2009). Voluntary Carbon Markets : An International Business Guide to What They Are and How They Work. London: Earthscan

Bumpus, A. G., \& Liverman, D. M. (2008). Accumulation by Decarbonization and the Governance of Carbon Offsets. Economic Geography, 84(2), 127-155. doi: 10.1111/j.1944-

8287.2008.tb00401.x

Chang, Y.-C., \& Wang, N. (2010). Environmental regulations and emissions trading in China. Energy Policy, 38, 3356-3364. 
China Business News. (2011). Permit allocations uncertain, carbon exchanges not yet through bottleneck, 23 November. Available at http://www.yicai.com/news/2011/11/1219852.html (in Chinese). Accessed 11 May 2014.

Christoff, P. (2010). Cold climate in Copenhagen: China and the United States at COP15. Environmental Politics, 19(4), 637-656.

Du, L., Mao, J., \& Shi, J. (2009). Assessing the impact of regulatory reforms on China's electricity generation industry. Energy Policy, 37(2), 712-720. doi: 10.1016/j.enpol.2008.09.083

Ellerman, A. D., Convery, F. J., \& Perthuis, C. D. (2010). Pricing carbon : the European Union Emissions Trading Scheme Cambridge, UK: Cambridge University Press.

Fan, G., Stern, N., Edenhofer, O., Xu, S., Eklund, K., Ackerman, F., et al. (2011). The economics of climate change in China: An Overview of the Possible. In G. Fan, N. Stern, O. Edenhofer, S. Xu, K. Eklund, F. Ackerman, L. Li \& K. Hallding (Eds.), The economics of climate change in China : towards a low-carbon economy. London: Earthscan.

Fankhauser, S. (2011). Carbon Trading: A good idea is going through a bad patch. The European Financial Review, April, 32-35.

Gilley, B. (2012). Authoritarian environmentalism and China's response to climate change. Environmental Politics, 21(2), 287-307. doi: 10.1080/09644016.2012.651904

Grubb, M. (2012). Cap and trade finds new energy. Nature, 491(29 November), 666-667.

Grubb, M., Laing, T., Counsell, T., \& Willan, C. (2011). Global carbon mechanisms: lessons and implications. Climatic Change, 104(3-4), 539-573. doi: 10.1007/s10584-009-9791-z

Guan, D., \& Hubacek, K. (2010). China can offer domestic emission cap-and-trade in post 2012. Environmental Science \& Technology, 44(14), 5327-5327. doi: 10.1021/es101116k

Han, G., Olsson, M., Hallding, K., \& Lunsford, D. (2012). China's Carbon Emission Trading: An Overview of Current Development. Stockholm: FORSE and Stockholm Environment Institute.

Huang, Y. (2013). Policy experimentation and the emergence of domestic voluntary carbon trading in China. East Asia, 30(1), 67-89.

Jiang, K., Zhuang, X., Miao, R., \& He, C. (2013). China's role in attaining the global $2^{\circ} \mathrm{C}$ target. Climate Policy, 13(sup01), 55-69. doi: 10.1080/14693062.2012.746070

Jotzo, F. (2013). Emissions trading in China: Principles, design options and lessons from international practice CCEP Working Paper 1303, May 2013. Canberra: Crawford School of Public Policy, The Australian National University.

Jotzo, F., De Boer, D., \& Kater, H. (2013). China Carbon Pricing Survey 2013. Beijing: China Carbon Forum.

Kossoy, A., \& Guigon, P. (2012). State and Trends of the Carbon Market 2012. Washington, DC. p. 94100: The World Bank.

Lin, A., \& Yang, F. (2012). China's carbon tax is very real China Dialogue 27 January. Available at http://www.chinadialogue.net/article/show/single/en/4742-China-s-carbon-tax-is-very-real. Accessed 11 May 2014.

Liu, J. Z. (2010). A study of China's energy-saving and carbon trading mechanism (wǒ guó jiē néng yǔ dī tàn de jiāo yì shì chăng jī zhì yán jiū). Shanghai: Fudan University Press (in Chinese).

Liu, S., \& Xu, N. (2012). Data gaps hobble carbon trading China Dialogue 9 August. Available at http://www.chinadialogue.net/article/show/single/en/5093-Data-gaps-hobble-carbontrading. Accessed 11 May 2014.

Lo, A. Y. (2010). Active conflict or passive coherence: The political economy of climate change in China. Environmental Politics, 19(6), 1012-1017.

Lo, A. Y. (2012). Carbon Emission Trading in China. Nature Climate Change, 2(11), 765-766.

Lo, A. Y. (2013). Carbon trading in a socialist market economy: Can China make a difference? Ecological Economics, 87(0), 72-74. 
Meckling, J. (2011). Carbon coalitions : business, climate politics, and the rise of emissions trading. Cambridge, Mass: MIT Press.

Mol, A. P. J. (2006). Environment and Modernity in Transitional China: Frontiers of Ecological Modernization. Development and Change, 37(1), 29-56. doi: 10.1111/j.0012155X.2006.00468.x

Mol, A. P. J. (2009). Urban environmental governance innovations in China. Current Opinion in Environmental Sustainability, 1(1), 96-100. doi: 10.1016/j.cosust.2009.07.002

$\mathrm{Mol}$, A. P. J. (2012). Carbon flows, financial markets and climate change mitigation. Environmental Development, 1(1), 10-24.

Mol, A. P. J., He, G., \& Zhang, L. (2011). Information disclosure in environmental risk management: Developments in China. Journal of Current Chinese Affairs, 40(3), 163-192.

National Development and Reform Commission. (2007). China's National Climate Change Programme. Beijing: National Development and Reform Commission, the People's Republic of China.

National Development and Reform Commission. (2011). Notice on the commencement of carbon trading pilot projects. Beijing: National Development and Reform Commission, the People's Republic of China.

Newell, P., \& Paterson, M. (2010). Climate capitalism : global warming and the transformation of the global economy Cambridge: Cambridge University Press.

Partnership for Market Readiness. (2013). China: Final Market Readiness Proposal. Presentation at the PMR Partnership Assembly in Washington, DC in 11 March 2013. Washington, DC: Partnership for Market Readiness

Paterson, M. (2010). Legitimation and Accumulation in Climate Change Governance. New Political Economy, 15(3), 345-368. doi: 10.1080/13563460903288247

Paterson, M. (2012). Who and what are carbon markets for? Politics and the development of climate policy. Climate Policy, 12(1), 82-97. doi: 10.1080/14693062.2011.579259

Perdan, S., \& Azapagic, A. (2011). Carbon trading: Current schemes and future developments. Energy Policy, 39(10), 6040-6054. doi: 10.1016/j.enpol.2011.07.003

Pezzey, J. C. V., \& Jotzo, F. (2013). Carbon tax needs thresholds to reach its full potential. Nature Clim. Change, 3(12), 1008-1011.

Sautter, J. A. (2009). Clean Development Mechanism in China: Assessing the Tension between Development and Curbing Anthropogenic Climate Change. Virginia Environmental Law Journal, 27(1), 91-118.

Schroeder, M. (2009). Utilizing the clean development mechanism for the deployment of renewable energies in China. Applied Energy, 86(2), 237-242.

Sorrell, S., \& Sijm, J. (2003). Carbon Trading in the Policy Mix. Oxford Review of Economic Policy, 19(3), 420-437. doi: 10.1093/oxrep/19.3.420

Spaargaren, G., \& Mol, A. P. J. (2013). Carbon flows, carbon markets, and low-carbon lifestyles:reflecting on the role of markets in climategovernance. Environmental Politics, 22(1), 174-193. doi: 10.1080/09644016.2013.755840

Spash, C. L., \& Lo, A. Y. (2012). Australia' s Carbon Tax: A Sheep in Wolf's Clothing? The Economic and Labour Relations Review, 23(1), 67-86.

Stadelmann, M., Michaelowa, A., \& Roberts, J. T. (2013). Difficulties in accounting for private finance in international climate policy. Climate Policy, 13(6), 718-737. doi:

10.1080/14693062.2013.791146

State Council. (2008). China's Policies and Actions for Addressing Climate Change. Beijing: State Council, People's Republic of China. 
State Council. (2011). Decision of the State Council to Strengthen the Discipline of Various Exchanges to Avoid Financial Risks [2011 No. 38]. Beijing: State Council.

State Council. (2011a). The Twelfth Five-Year Plan for National Economic and Social Development (in Chinese). Beijing: State Council, People's Republic of China.

State Council. (2011c). Working Plan for Greenhouse Gas Control under the 12th Five-Year Plan (No. 41) (in Chinese). Beijing: State Council, People's Republic of China.

Sun, C. (2012). China's Macro Policy of Controlling Greenhouse Gas Emission and Exploration of Market Mechanism. Beijing: Department of Climate Change, National Development and Reform Commission, China. Presentation at the Partnership for Market Readiness's Meeting in March 2012 (http://www.thepmr.org/country/china-0). Accessed 11 May 2014.

Tao, J., \& Mah, D. N.-y. (2009). Between market and state: Dilemmas of environmental governance in China's sulphur dioxide emission trading system. Environment and Planning C: Government and Policy 27(1), 175-188.

The Climate Group. (2013). Shaping China's Climate Finance Policy. London: The Climate Group.

Tsang, S., \& Kolk, A. (2010). The evolution of Chinese policies and governance structures on environment, energy and climate. Environmental Policy and Governance, 20(3), 180-196. doi: 10.1002/eet.540

Wang, Q. (2013). China has the capacity to lead in carbon trading. Nature, 493 (17 January 2013), 273.

Wang, S. (2014). Recent Development of Chinese ETS. Beijing: Department of Climate Change, National Development and Reform Commission, China. Presentation at the Partnership for Market Readiness's Meeting at Mexico City(http://www.thepmr.org/country/china-0). Accessed 11 May 2014.

Wang, S., \& Duan, M. (2013). China: Design of Domestic Emissions Trading Scheme. Beijing: Presentation at the Partnership for Market Readiness's Meeting at Washington, DC (http://www.thepmr.org/country/china-0). Accessed 11 May 2014.

Wang, Y., Liu, Q., \& Chen, B. (2012). 2012 China Climate Finance Report: Climate Capital Flow. Beijing: Central University of Finance and Economics and The Climate Group.

Wang, Y. M., \& Pan, S. M. (2009). Status \& trends of China carbon trading market under financial crisis. Economic Theory and Business Management (in Chinese), 11, 57-63.

Wu, Q. (2011). Policy and Politics of a Carbon Market in China. In J. Peetermans (Ed.), Greenhouse gas market report 2011: Asia and Beyond: the Roadmap to Global Carbon \& Energy Markets (pp. 22-25). Genève, Switzerland: International Emissions Trading Association.

Xinhua News Agency. (2011). Domestic carbon exchanges blossom and most come at a loss. 28 September. Available at http://news.xinhuanet.com/fortune/2011-09/28/c 122097917.htm (in Chinese). Accessed 11 May 2014.

Yu, G., \& Elsworth, R. (2012). Turning the Tanker: China changing economic imperatives and its tentative look to emissions trading. London: Sandbag Climate Campaign.

Zhang, Z. (2007). Why has China not embraced a global cap-and-trade regime? Climate Policy, 7, 166-170.

Zhang, Z. (2011). Assessing China's carbon intensity pledge for 2020: stringency and credibility issues and their implications. Environmental Economics and Policy Studies, 13(3), 219-235. 